\title{
Examination of the Availability and Relevancy of Transitional Programmes for Adolescents with Hearing Impairment in Schools in Bulawayo.
}

\author{
Sibanda Patrick, and Nkala Printah Printer
}

\begin{abstract}
This study sought to establish the availability and relevancy of transitional programmes for adolescents with hearing impairment in schools in Bulawayo. According to Lehmann, Ravies and Lourin (2003), there is no amount of modern special educational programming that would be complete without making reference to transition from school to community life. A descriptive survey design was employed in conducting the study while a questionnaire and face to face interviews were used in triangulation to elicit data. Data were presented in tables, and bar-charts and analysed using frequency counts, percentages, Likert Scale and descriptive summaries. The major findings of the study were that, while some vocational subjects were available and appeared relevant to the future needs of the adolescents with hearing impairment in schools in Bulawayo, the subjects were largely offered at theoretical level. There were no work experience and attachment arrangements save for one school which however relied on one local factory which was facing collapse at the time of the study. This made the transition programmes generally irrelevant to the real future lives of the adolescents. The study also found out that, the schools did not deliberately teach social skills to adolescent with hearing impairment often due to communication barriers. From the findings, the study concluded that what schools in Bulawayo regarded to be transition programmes were in effect isolated transition activities that hardly constituted a programme. In any case, these activities did not adequately prepare the adolescents with hearing impairment in schools in Bulawayo for adult life. The study went on to recommended staff development of school administrators and teachers in transition programming. The study also recommend work experience and attachment arrangements, multi-stakeholder participation, formulation of specific policies and improvement of resourcing of transition programmes for adolescents with hearing impairment in Bulawayo.
\end{abstract}

Keywords: - Adolescence; Transitional Programmes; Hearing Impairment

\section{BACKGROUND TO THE STUDY}

The general purpose of any educational curriculum is to prepare learners for the future and to facilitate personal independence. The ultimate goal of education is to facilitate a smooth transition from adolescence to adulthood and from school to community living. The centrality of educational curricula in the preparation of students for the future becomes more essential with regards to adolescents. Hallahan and Kauffman(1997) report that, a plethora of studies point to the indispensability of a deliberate transition curriculum for adolescents with disabilities since a high percentage of them have difficulty in making the transition to adulthood. Winzer (1990) observed that data on young handicapped adults indicate that despite special programmes, many adolescents with disabilities still experience major difficulties in bridging the gap between school and community work and living. For this reason, Zigmond and Sainato (2001) conjecture that schools have been assigned more responsibility to prepare children and youths with disabilities for the ever widening range of challenges, problems and opportunities they will face as adults. Whether schools, especially in Bulawayo, have taken this responsibility is yet to be proved. There is actually no amount of modern special educational programming that would be complete without making reference to transition from school to community life (Lehmann, Ravies and Lourin, 2003). In the United States of America, schools have been far more passive in their approach to transitional programming particularly in relation to employment preparation of adolescents with disabilities (Hardman, Drew and Egan, 1999). Hann and Levison (2002) observe that in Africa and Asia, the situation is more appalling. The investigators note that very few studies have been published in response to transitional programmes in Africa and Asia. On these bases, the researchers found it imperative to interrogate the availability and relevance of transitional programmes for adolescents with hearing impairment in Bulawayo in particular. Another revelation is that, limited interest has been shown in the study of the relevance of transitional programmes for students with disability other than those with mental retardation and those with learning disabilities (Test, Karvoness, Wood and Algozzine, 2003). From the above analysis, it would appear that the study of transition programming for adolescents with hearing impairment might not have generated much interest in the past yet many of the adults with hearing impairment particularly in Bulawayo are hardly employed suggesting that they lack personal independence. 


\subsection{Problem Definition}

Transition programmes designed for adolescents with hearing impairment are expected to prepare learners for the future and to enhance personal independence. Many of the adolescents with hearing impairment in Bulawayo are under employed and lack positive independent living skills.

\subsection{Related Questions}

1.2.1 What transitional programmes are available to adolescents with hearing impairment in schools in Bulawayo?

1.2.2 How relevant are the transitional programmes available in schools in Bulawayo to the future needs of adolescents with hearing impairment?

\subsection{Sub-Problems}

1.3.1 What vocational subjects are offered to adolescents with hearing impairment in schools in Bulawayo, to prepare them for employment?

1.3.2 How relevant are the vocational subjects offered to adolescents with hearing impairment in schools in Bulawayo to their future needs.

1.3.3 How relevant are the social living skills taught to adolescents with hearing impairment in schools in Bulawayo to the demands of adult life?

1.3.4 What policies mandate the provision of transitional programmes for adolescents with hearing impairment in schools in Bulawayo?

1.3.5 What resources are available to adolescents with hearing impairment in schools in Bulawayo to facilitate their transition to adulthood?

\subsection{Primary Purpose of the Study}

This study sought to examine the availability and relevancy of transitional programmes for adolescents with hearing impairment in schools in Bulawayo.

\subsection{Conceptual Framework (Literature Review)}

The study examined literature related to transitional programmes in respect of adolescents with hearing impairment. Conceptions of adolescence, transition to adulthood and exploration of theoretical underpinnings of transitional programmes for adolescents with hearing impairment shall were reviewed in order to put the current study into focus. Theories of adolescent development and of transition were analysed and previous researches on the same subject evaluated as a way of conceiving a theoretical foundation of the study and of confirming the knowledge gap this study is seeking to bridge.

\subsubsection{Conceptual Analysis of Adolescence}

Adolescence is a stage of human development which transits from late childhood to early adulthood. For Hardman, Drew and Egan (1999), adolescence brings on a growing awareness of the requirements of adult life relative to sex-role expectations, personal appearance and hygiene. The authors observe that sexual interests develop as well as dramatic physical and psychological changes occur during adolescence. Elmen and Offer (1991) view adolescence as an age range from twelve to nineteen years whereas Santrock (2002) view adolescence as the developmental period of transition from childhood to early adulthood, entered at approximately ten to twelve years of age and ending at eighteen to twenty-two years of age. Atkinson, Atkinson, Smith and Hilgard (1987) earlier on observed that the age limits of adolescence are not clearly specified. The authors further implored that, during adolescence, the individual establishes an identity and faces the task of deciding how to earn a living.

According to Atkinson et al (1987:95), “....adolescence is a gradual transition to adult status... a period in which to develop skills and to improve for the future but tends to produce a period of conflict and vacillation between dependence and independence from adults." For Sailor and Guess (1983), from the traditional view, adolescence is a period full of storm and stress, contradictions, wide swings in mood and emotions and turmoil and identity diffusion. With regards to adolescents with hearing impairment, when the controversies of adolescence are superimposed upon the burdens of disability, more conflict and strife strikes, necessitating the need to deliberate on transitional programming (Athey, 1985). However, Goldberg (1984), earlier on argued 
that, adolescents with disabilities such as hearing impairment, react to adolescence in the same manner as their peers.

In addition, adolescence can be taken as a matter of social experience and cultural definition. For example, Priestley (2003:90) states; “... adolescents take on the rights and responsibilities of adulthood at different ages in different societies and circumstances." From this point of view, barriers to full adult status may exist for adolescents with hearing impairment unless formal transitional programmes are provided. According to MacDonald, Mason, Shildrick, Webster, Johnstone and Ridley (2001), it is important to see adolescence as a key transitional phase for everyone regardless of their ability or disability. In this content, any study of adolescence becomes a study of examining shifting social, economic and cultural processes that should shape this period of life-course.

\subsubsection{Theories of Adolescent Development}

Since adolescents with disabilities are an extremely diverse group in terms of specific disability, personal resources and adjustment, it is important that studies about them take into account theories of development(Lerner, 1996). Piaget (1886-1980) through his cognitive theories declared that the reasoning abilities of adolescents are more advanced than those of younger children but not quite as sophisticated as those of adults. Cognitive theories are based on the premise that adolescents have shifted away from concrete thinking to more flexible reasoning and problem solving strategies. Kohlberg (1996) postulated that adolescents display sophisticated moral reasoning skills that distinguish them from younger children. However, Boothroyd (1982) cited in Patton, Payne, Kauffman, Brown and Payne (1987) is concerned that hearing impairment may have debilitating consequences on perceptional communication, cognitive, social emotional and vocational development among others. Martin ( 1991) challenges this notion by pointing out that adolescents with hearing impairment can reason as logically and score as high as their peers without hearing impairment on performance tasks as long as they are given adequate time, attention and support.

The most controversial theories of adolescent development are the psychodynamic theories propounded by Freud (1856-1939). Freud claims that, pubertal hormones exert direct influence on adolescent behaviour and projects adolescence as a reaction to puberty and a stage of turmoil. In response to Freud's views of adolescence, Jaffe (1998:55) argues, "Research contradicts this stereotype of the adolescents in turmoil."

Similarily, Erikson (1968) conceives adolescence as the identity versus identity diffusion stage of development and believes that hearing impairment has the propensity to fuel identity diffusion especially when the society perceives deaf adolescents as different from and inferior to their peers.

Behavioural models are yet other credible theories of adolescent development which came about as a reaction to psychodynamic models. According to Jaffe (1998), behavioural models are based on the premise that adolescent behavior is learned and maintained according to the principles of classical conditioning. Klacynski (1990) asserts that the Skinnerian view of adolescent behavior emphasizes the importance of behavioural consequences (rewards and punishment) in shaping adolescents into responsible adults. At the other extreme, humanistic views of adolescent development proposed by Maslow (1971) and Rogers (1961) fiercely refute the behaviourists' mechanistic conceptions of adolescent development, Freud's storm and stress and Piaget's stage theories of human development. Instead, humanists view a person from a positive stance. They propose that any human being has great potential and capability to define his/her own destiny.

\subsubsection{Adolescence and Hearing Impairment}

Transition to adulthood may be complicated for adolescents but not as a result of implicit effects of hearing impairment itself, but due to the effects of societal reactions to disability, (Naaron, Decoufe and Cadwell, 1990). It is however indisputable that disability such as hearing impairment can change the way the adolescent sees life. The consequences of disability often preclude adolescents from the possibility of gaining employment and accessing social services. In a study by Mitchell (1999), disabled adolescents experienced delayed transition. The study however acknowledged that this could have been a result of very low expectations of them by their parents and society. From this perspective, a hearing impairment per se should not preclude the adolescent from a smooth and successful transition to adulthood.

Marshack (1993) is of the view that, depending on the time of onset and severity of hearing impairment and level of societal acceptance and intervention, hearing impairment may delay transition to adulthood or even cause fixation. Hersen (1987), concur that, adolescents with profound hearing impairment manifest serious adjustment problems and lack self confidence, are isolated, usually depressed and have a negative self-esteem. All these behaviours have great implications for transition to adulthood. On these bases, Hann and Levinson (2002) justify formal transitional programmes for all adolescents with hearing impairment. 


\subsubsection{Transitional Programmes}

Transition is the passage or movement of individuals particularly from childhood to adulthood. Lenhmann et al, (2003) conceive transitional programmes as outcome oriented and co-ordinated activities designed to move students with disabilities from school to adulthood and community living. For all students, especially for those in high school, the school experience represents a period of transaction ' $\ldots$ between the security of the school and the complexity associated with the opportunities and risks of adult life' (Winzer, 1990:206). Hardman et al, (1999) add that, transitional programmes also include instruction, related services, community experiences development of employment and other post-school objectives. Within this context, transitional programmes are planned activities intended to help adolescents with hearing impairment to cope with the passage from the shelter of the school to the wider, more impersonal adult life (Levinson, 2002). Transition is however perceived differently in different cultures and societies. For example Priestley (2003) observes that in western societies entry into adulthood is defined individually, that is, in terms of financial or residential independence whereas in non-western societies, entrance into adulthood is defined by a specific social event such as marriage or a public rite of passage. As such, structural and time-framed conception of transition of adolescents with hearing impairment have a strong social connotation. Tisdall (2001) advises on the importance of acknowledging the cultural significance of disability in adolescence and transition and their relationship to the different idealized constructions of adulthood.

\subsubsection{Goals of Transitional Programmes and Services for Adolescents With Hearing Impairment}

The rationale for transitional programmes includes specific aims and objectives which depend on the individual needs, type and severity of disability, availability of resources and other factors. Gulliford (1973) says that the goal include the provision of opportunities and services that promote quality adult living, maintenance of community integration and the maximization of productivity and independence. Hallahan and Kauffman (1997) assert that the major goal is to improve the quality of life of persons with disabilities so that they may gain personal independence. Accordingly, the major goal of transitional services for adolescents with hearing impairment is to provide special assistance needed by the adolescents that will help them achieve the most rewarding productive, independent and integrated adult life possible. To achieve these goals, Goldberg (1984) suggests that adolescents with disabilities need services to assist them sort out problems of separation, independence, sexual identity and above all the usual vocational choice, aspiration, interests, adjustment and satisfaction. Transitional services for adolescents with hearing impairment entail training in community living and employability skills.

\subsubsection{Transition Programmes for Adolescents with Hearing Impairment}

Hardman et al (1999) identify career education, vocational education, work experience and communityreferenced instruction as some of the several approaches to training for employment which should be adopted and used with students with disabilities. Personal hygiene, reproductive health, social skills and self help skills should also form the core of a transitional programme for adolescents with hearing impairment. Consistent with Hardman et al (1999)'s observation, Flemming (1985) is of the view that career education is important as it facilitates positive career behavior through awareness of available resources and opportunities that suit the needs of students with hearing impairment. In addition, Goldberg (1984) earlier implored that vocational education for disabled adolescents requires programming that can develop individual work habits and skills through real life work experiences. Over and above occupational skills, adolescents with hearing impairment require appropriate skills for successful community and social living. The importance of community and social living skills should not be underestimated in any transitional programme (Levinson, 2002).

Wall (2009) equals the importance of competence in social and interpersonal skills and home living to that of employability skills and advises that these skills should be taught both in the classroom and in the community setting. In addition, Jaffe (1998) posits that, adolescents with hearing impairment need sexeducation to protect themselves from unfavorable consequences of sexual activity such as teenage pregnancy and sexually transmitted infections including HIV/AIDS. Nziramasanga(1999) emphasizes that need to expose adolescents with disabilities to leisure and recreation activities while they are at school. This idea forms a basis for the argument for provision of formal transitional programmes to adolescents with disabilities.

\subsection{Methodology}

The study used the descriptive survey design to describe accurately, the nature of the existing conditions of transitional programming and to identify standards against which the existing conditions could be compared. The descriptive survey design enabled the researcher to collect large amounts of data in a short space of time. To offset bias, the researcher used structured interviews and questionnaires in conjunction with observation. Methodological triangulation increased interpretability, meaningfulness, reliability and validity of data findings (Cohen, Manion and Morrison, 2007). 


\subsubsection{Population and Sample}

The population of interest of this study comprised all adolescents with hearing impairment still attending school, all the teachers and all the administrators of schools that enroll students with hearing impairment in Bulawayo Metropolitan Province. A sample of thirty adolescents with hearing impairment was chosen. Simple random sampling was adopted for the adolescents. For teachers, coincidental sampling was used to involve those who were present on the day of the researchers' visit.

\subsubsection{Data Presentation and Analysis Methods}

Data were presented on tables and bar-charts. Frequency counts, percentages and descriptive summaries were used in conjunction with a Three Point Likert Scale to analyse the data.

\subsection{Findings}

1.8.1 Demographic Data

Table 1: Distribution of Teachers by Highest Professional Qualification $(\mathbf{n}=\mathbf{2 0})$

\begin{tabular}{|l|c|c|}
\hline Highest Professional Qualification & $\mathbf{n}$ & $\mathbf{\%}$ \\
\hline CE/DE (Without Sped) & 2 & 10 \\
\hline CE/DE (Sped) & 15 & 75 \\
\hline Bachelor's Degree (Without Sped) & 0 & 0 \\
\hline Bachelor's Degree (Sped) & 3 & 15 \\
\hline Post Graduate Degree & 0 & 0 \\
\hline Total & $\mathbf{2 0}$ & $\mathbf{1 0 0}$ \\
\hline
\end{tabular}

Data indicate that the majority of teachers $(75 \%)$ who taught adolescents with hearing impairment in Bulawayo held Certificates or Diplomas in Special Education while 3(15\%) held a Bachelor's degree in Special Education. The other 2(10\%) of the teachers did not hold a Special Education qualification yet they taught adolescents with hearing impairment. None of the teachers held a Post Graduate Degree qualification.

Table 2 : Distribution of Teachers by Area of Specialisation in Special Education (n=20)

\begin{tabular}{|l|c|c|}
\hline Area of Specialisation & $\mathbf{n}$ & $\mathbf{\%}$ \\
\hline Mental Retardation & 3 & 15 \\
\hline Learning Disabilities & 0 & 0 \\
\hline Hearing Impairment & 15 & 75 \\
\hline Visual Impairment & 0 & 0 \\
\hline Other & 0 & 0 \\
\hline None & 2 & 10 \\
\hline Total & 20 & 100 \\
\hline
\end{tabular}

The table indicates that $15(75 \%)$ of the teachers specialized in hearing impairment while $3(15 \%)$ specialized in mental retardation and 2(10\%) were not specialist teachers at all.

Table 3: Enrolment of Adolescents with Hearing Impairment Gender ( $n=90)$

\begin{tabular}{|l|c|c|}
\hline Gender & n & $\mathbf{4 0}$ \\
\hline Males & 36 & 40 \\
\hline Females & 54 & 60 \\
\hline Total & 90 & 100 \\
\hline
\end{tabular}

In Table 3, 36(40\%) of the adolescents with hearing impairment who were enrolled in the twelve schools were males while 54(60\%) were females. 
1.8.2 Research Question: What vocational subjects are taught to adolescents with hearing impairment in schools in Bulawayo?

Figure 1: Bar Chart Showing Frequency of Vocational Subjects

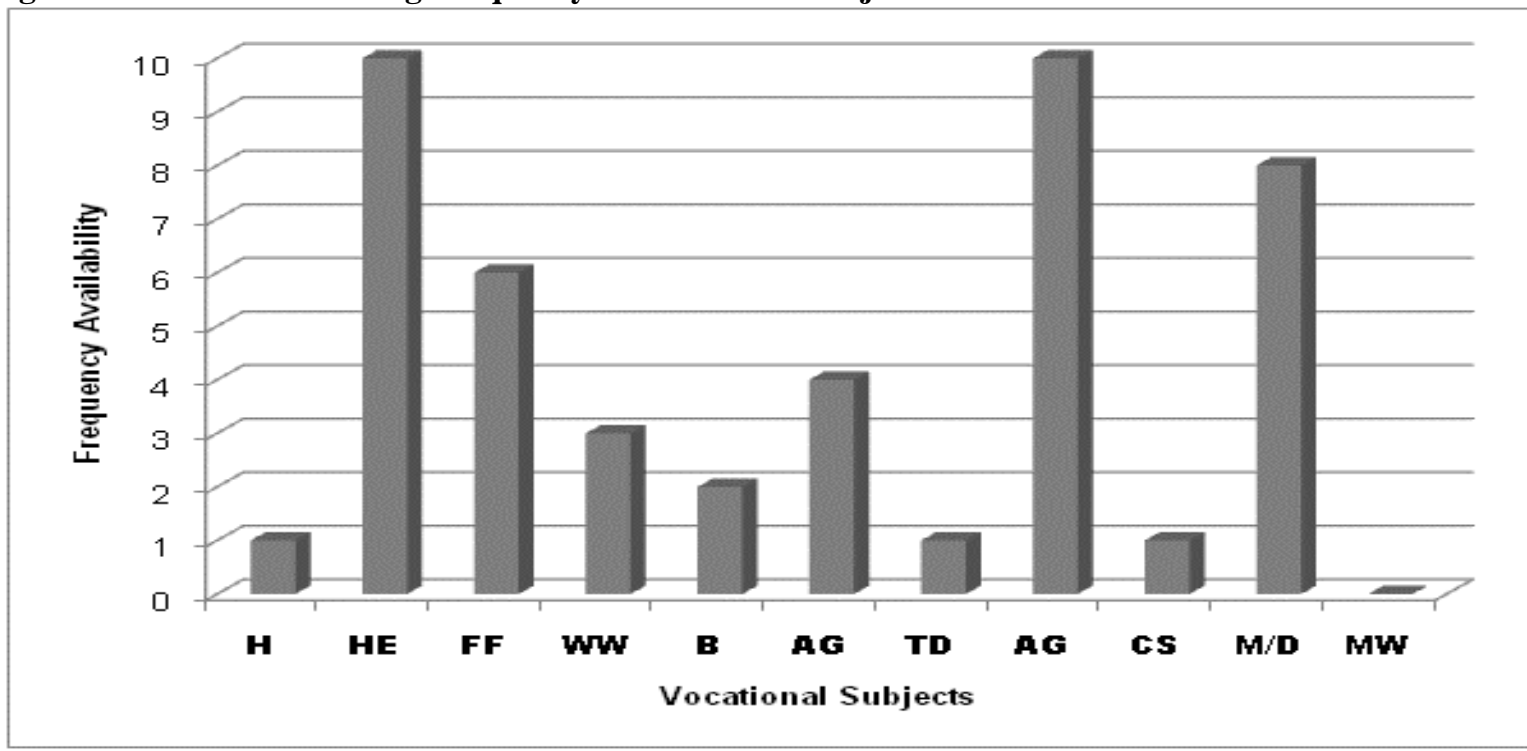

\section{$\underline{\text { KEY }}$}

H - Hairdressing

A - Art

AG - Agriculture

H.E - Home Economics F.F - Fashion \& Fabrics

$$
\text { M-Music WW- Wood Work B-Building }
$$

TD - technical Drawing CS - Computer Science

Figure 1 illustrates the number of schools that taught each of the vocational subjects to adolescents with hearing impairment. Home Economics and Art were taught in ten of the schools while eight of the schools taught Music and six taught Fashion and Fabrics to adolescents with hearing impairment. Hairdressing, Technical Drawing and Computer Science were the least preferred subjects due to lack of relevant resources.

1.8.3 Research Question: What social living skills are taught to adolescents with hearing impairment in schools in Bulawayo?

Figure 2: Bar-Chart Showing Frequency of Availability of Social Living Skills

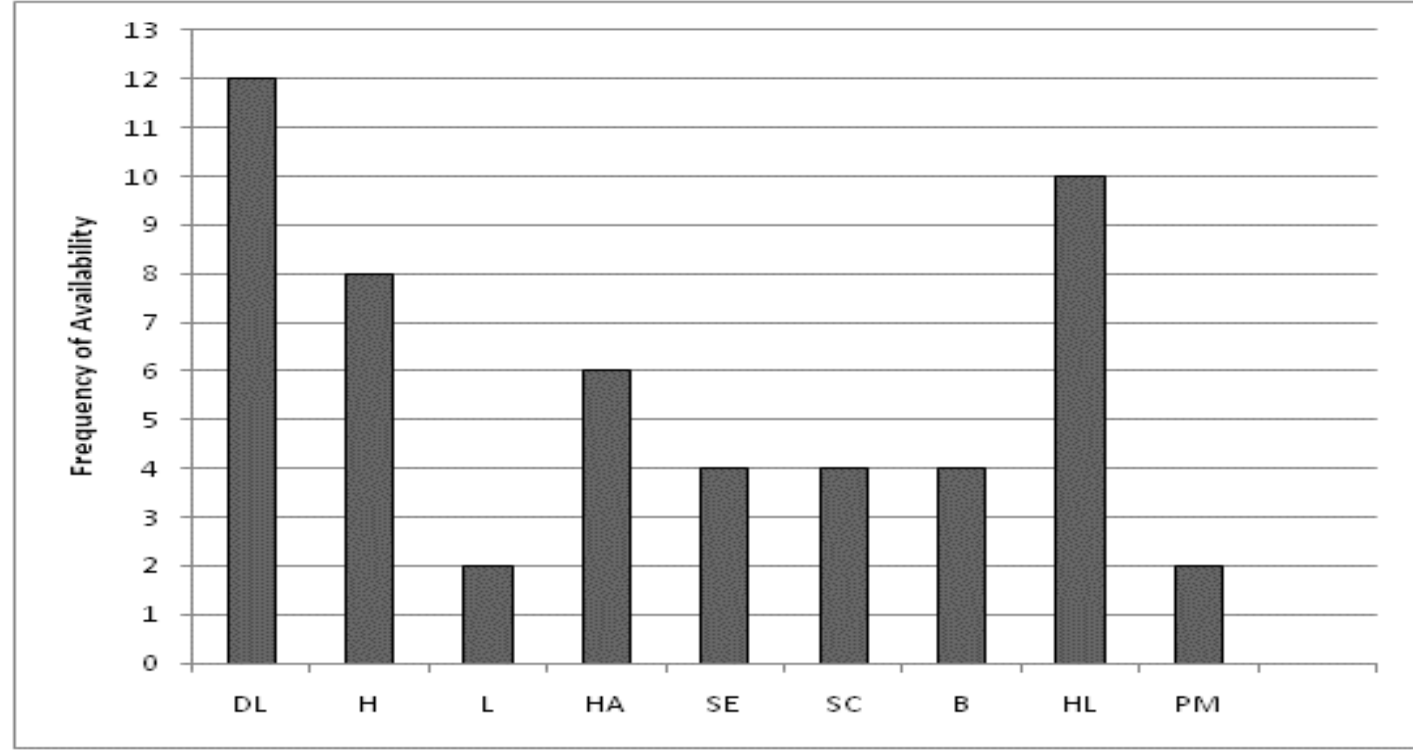

$$
\begin{aligned}
& \frac{\text { KEY }}{\mathrm{DL}-\text { Daily Living }} \\
& \text { L- Leadership } \\
& \text { HL - Home Living } \\
& \text { SC }- \text { Social Conventions }
\end{aligned}
$$

$\mathrm{H}$ - Hygiene

HA - HIV / AIDS

B - Budgeting

$\mathrm{P} / \mathrm{M}$ - Parenting \& Marriage 
Figure 2 indicates that all the twelve schools taught daily living skills while ten taught home living skills. Eight of the schools taught hygiene and six indicated that they taught adolescents with hearing impairment about HIV/AIDS. Four schools taught sex education, budgeting and social conventions while two said they taught leadership and marriage and parenting to adolescents with hearing impairment.

1.8.4 Research Question: What employment preparation programmes are available to adolescents with hearing impairment in schools in Bulawayo?

Figure 4: Pie Chart Showing Frequencies of Availability of Employment Preparation Programmes
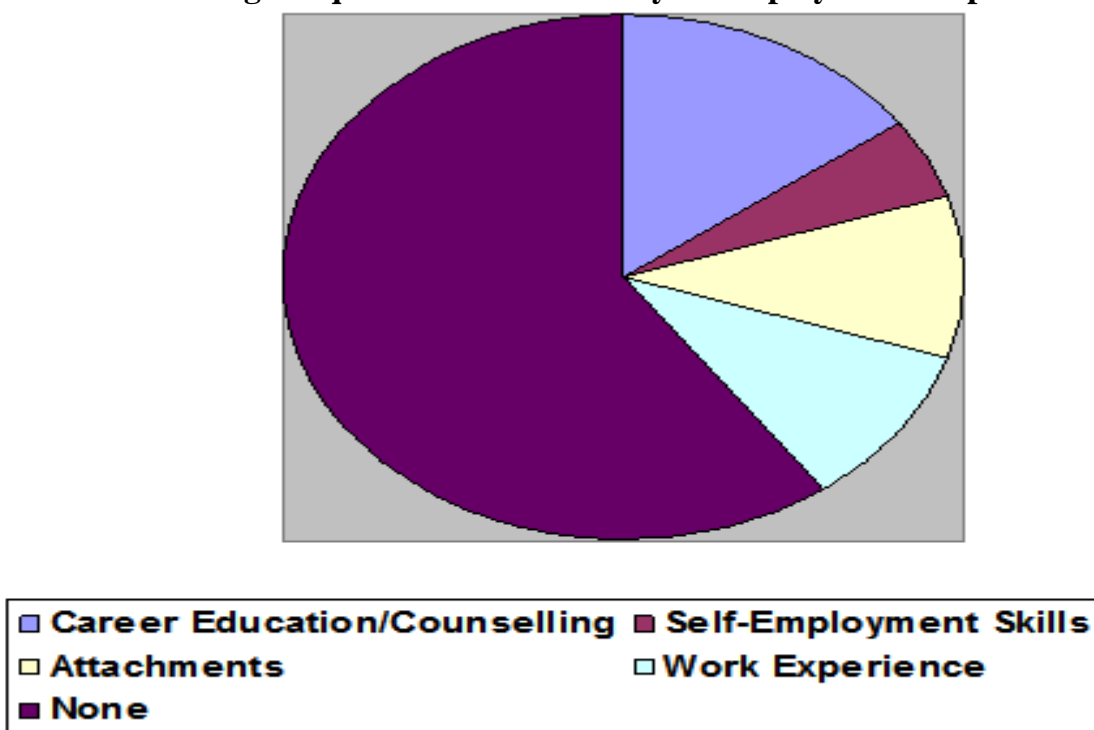

According to figure $4,7(58.3 \%)$ of the schools did not have any employment preparation programmes. One $(8.3 \%)$ of the schools in each case taught self-employment skills and made some form of attachments and work experience arrangements for adolescents with hearing impairment. The other 2(16.7\%) schools offered career education/counselling to the adolescents.

1.8.5 Research Question: How relevant are the transitional programmes offered in schools in Bulawayo to the needs of adolescents with hearing impairment?

Table 6: Teachers' Perceptions About the Relevance of Transitional Programmes (n=20)

\begin{tabular}{|l|c|c|c|c|c|c|c|c|}
\hline Statement & \multicolumn{2}{|c|}{$\mathrm{A}$} & \multicolumn{2}{c|}{$\mathrm{U}$} & \multicolumn{2}{c|}{$\mathrm{D}$} & \multicolumn{2}{c|}{ Total } \\
\hline $\begin{array}{l}\text { The school provides adequate resources for } \\
\text { vocational subjects. }\end{array}$ & $\mathrm{n}$ & $\%$ & $\mathrm{n}$ & $\%$ & $\mathrm{n}$ & $\%$ & $\mathrm{n}$ & $\%$ \\
\hline $\begin{array}{l}\text { Teachers use Individualized Transitional } \\
\text { Plans to teach adolescents with H.I. }\end{array}$ & 6 & 30 & 9 & 45 & 5 & 25 & 20 & 100 \\
\hline $\begin{array}{l}\text { The transitional programmes offered prepare } \\
\text { adolescents with H.I for adulthood. }\end{array}$ & 4 & 20 & 5 & 25 & 11 & 55 & 20 & 100 \\
\hline $\begin{array}{l}\text { The transitional programmes equip } \\
\text { adolescents with H.I with adequate adulthood } \\
\text { community skills. }\end{array}$ & 4 & 20 & 5 & 25 & 11 & 55 & 20 & 100 \\
\hline $\begin{array}{l}\text { Adolescents with H.I who went through the } \\
\text { transitional programmes at this school } \\
\text { integrate well into the community. }\end{array}$ & 3 & 15 & 8 & 40 & 9 & 45 & 20 & 100 \\
\hline $\begin{array}{l}\text { Former students secured employment on the } \\
\text { basis of the skills taught in the transitional } \\
\text { programmes. }\end{array}$ & 10 & 50 & 1 & 5 & 9 & 45 & 20 & 100 \\
\hline $\begin{array}{l}\text { The transitional programmes adequately } \\
\text { prepares adolescent with H.I. for } \\
\text { employment. }\end{array}$ & 10 & 50 & 1 & 5 & 9 & 45 & 20 & 100 \\
\hline
\end{tabular}


$\underline{\text { KEY }}$

$\frac{\mathrm{A}-\mathrm{Agree}}{\mathrm{A}-U \text { Uncertain } \quad \text { D-Disagree }}$

Table 6 indicates that 13(65\%) of the teachers disagreed that their schools provided adequate resources for the vocational training of adolescents with hearing impairment, while 3(15\%) agreed and 4(20\%) were uncertain. Of the 20 teachers, 9(45\%) were uncertain, 6(30\%) agreed and 5(25\%) disagreed that they used Individual Transitional Plans to teach adolescents with hearing impairment. From the table, 11(55\%) of the teachers disagreed, 5(25\%) were uncertain and 4(20\%) disagreed that the transitional programmes they offered prepared adolescents with hearing impairment for adulthood. Nine $(45 \%)$ of the teachers disagreed that adolescents who had gone through the transitional programmes integrated well into the community while $8(40 \%)$ uncertain and $3(15 \%)$ disagreed. It is also clear from the table that, half $(50 \%)$ of the teachers observed that the transitional programmes offered by the schools helped adolescents with hearing impairment secure employment. Nine $(45 \%)$ teachers disagreed with and one uncertain about this assertion.

1.8.6 Question 1.5.3: How relevant are the vocational subjects offered in schools in Bulawayo to the future needs of adolescents with hearing impairment?

Perceptions of School Administrators About the Relevance of Transitional Programmes.

All the $12(100 \%)$ of the administrators of the schools that enrolled adolescents with hearing impairment were unanimous that the vocational subjects were relevant to the future needs of adolescents with hearing impairment. However, the administrators believed that, lack of resources compromised the relevancy of the subjects. Administrators of primary schools observed that, vocational subjects offered were not examinable leading to reduced seriousness on the part of both teachers and students. Secondary School Administrators on the other hand explained that, limited or complete lack of opportunities for vocational attachments and work experience for adolescents with hearing impairment made the subjects less relevant to the transition needs of the adolescents. One $(8.3 \%)$ of the administrators that enroll adolescents with hearing impairment, and was Head of a Special School believed that, the vocational subjects offered at the school were overly relevant. The Special School Head cited two of their former students with hearing impairment who graduated from universities before and several others who qualified from local technical colleges and were gainfully employed.

\subsubsection{Question 1.5.4.1: How relevant are the social living skills taught to adolescents with hearing} impairment in schools in Bulawayo to the demands of adult life?

Eleven $(91.7 \%)$ of the administrators of the schools that enrolled adolescents with hearing impairment suggested that, although teaching of the social living skills to the adolescents was either scarce or not practiced in their schools, the skills tended to be relevant to the demands of adult life. The school administrators also noted that, what made the teaching of the social living skills to be irrelevant to adolescents with hearing impairment was that it was done without proper regard for the communication needs of the adolescents and that it was often done by teachers who could not sign. The administrators expressed concern that the adolescents with hearing impairment were not benefiting much from the mass teaching of community living kills, for instance.

\section{Perceptions of Adolescents With Hearing Impairment About the Relevance of Transitional Programmes} $(\mathbf{n}=\mathbf{3 0})$

In order to authenticate the teachers' and the school administrators' views, the study also sought the students' perceptions on the availability and relevancy of the transitional programmes.

\subsubsection{Question 1.5.3: How relevant are the vocational subjects offered in schools in Bulawayo to the future needs of adolescents with hearing impairment?}

Twenty four $(80 \%)$ of the adolescents with hearing impairment expressed ignorance about the relevancy of the vocational subjects because they were either not benefiting during lessons due to poor communication or were not doing the subjects at all. The other 4(13.3\%) implied that, although the subjects were important for their future needs, they had difficulties paying for input materials and understanding the teachers who taught them. Since the teachers could not understand Sign Language. The adolescents were also worried that, in some cases, there were no teachers for the subjects. The other $2(6,78 \%)$ of the adolescents with hearing impairment, thought that the subjects were relevant to their future needs since some of their peers who completed were working on the basis of those subjects. 


\subsubsection{Question 1.5.4: How relevant are the social living skills taught to adolescents with hearing} impairment in schools in Bulawayo to the demands of adult life?

Twenty four $(80 \%)$ of the adolescents with hearing impairment had isolated understanding of the social living skills and could hardly report on their relevancy. The other 6(20\%) were unanimous that the social living skills helped them understand themselves and other people. They also revealed that the skills helped them become good future parents and stay safe from HIV and AIDS in particular.

\section{CONCLUSIONS}

On the basis of the findings of the study, the following conclusions were drawn:-

- Lack of resources and proper planning account for the irrelevancy of the transitional programmes in schools in Bulawayo to the future needs of adolescents with hearing impairment.

- The few vocational subjects offered did not adequately prepare adolescents with hearing impairment in schools in Bulawayo for employment and for adulthood because of lack of human and material resources as well as lack of attachment and work experience arrangements.

- Generally, the transitional programmes offered to adolescents with hearing impairment in the schools in Bulawayo did not adequately prepare the adolescents for future life.

- What schools regarded as transitional programmes were actually isolated activities which hardly constituted a programme.

\section{RECOMMENDATIONS}

On the basis of the findings of the study, the following recommendations were proffered for the attention of the Ministry of Education, Sport, Art and Culture.

- That the Ministry staff-develops all school administrators and teachers on transitional programming for adolescents with hearing impairment.

- The Ministry increases provision of resources to schools which enroll adolescents with hearing impairment. This should include deployment of qualified vocational trainers who can effectively communicate with adolescents with hearing impairment.

- It should be mandatory that all vocational subjects be examinable.

- That the Ministry arranges for mandatory, job attachments of adolescents with hearing impairment to industry, local business and technical colleges.

- That multiple stakeholders including government, industry, civil society and families of adolescents with disabilities be involved in the planning and implementation of transitional programmes.

\section{REFERENCES}

[1] Golberg, R.T (1984). Toward an Understanding of the Rehabilitation of the Disabled

[2] Adolescent. In Marineli, R.P. and dell Orto, A.E. (Eds. The Psychological and Social Impact of Physical Disability. New York : Springer Pub. Co.

[3] Hallahan, D.P. and Kauffman, J.M. (2000). Exceptional learners : Introduction to Special Education. ( $8^{\text {th }}$ Ed.) Boston: Allyn and bacon.

[4] Hallahan, D.P.and Kauffman,J.M. (2000).Eceptional Learners :Introduction to special Education. ( $8^{\text {th }}$ Ed).Boston: Allyn and Bacon.

[5] Hardman,M.L.,Drew,C.J. and Egan,M.W.(1999).Human Exceptionality:Society,School and Family.Boston:Allyn and Bacon.Jaffe, M.L.(1998).Adolescence. New York: John Wiley and Sons.

[6] Klaczynski, P.A(1990) Cultural Developmental Tasks and Adolescent Development :Theoretical and Methodological Considerations Adolescence.Vol 25 No.100(pages811-23).

[7] Lehmann,J.P, Davies, T.G and Laurin,K.M (2003). Listening to student Voices About Post Secondary Education. Educating Exceptional Children.Vol2 No.3 (pages206-10)

[8] Lerner, R. M.(1996). Relative Plasticity, Integration, Temporality and Diversity in Human Development: A Developmental Contextual Perspective About Theory, Process

[9] and Method. Developmental Psychology..Vol23 No 4 (pages781-6).

[10] Marsharck,M. (1993). Psychological Development of Deaf Children : New York: OUP

[11] Mitchell,W.(1999).Leaving Special School. The Next Step and Future Aspirations. Disability and Society. Vol14 No 6 (pages753-70)

[12] Naaroen,K.V.,Decoufle,P and Cauldwell, K. Prevalence and Characteristics of Children With Serious Hearing Impairment In Metropolitan Atlanta. Atlanta :MADDSP.

[13] Nziramasanga,C.T.(1999).Report of the Presidential Commission of Inquiry Into Education and Training. Harare : Government Printers. 
[14] Piaget,J.(1997).Intellectual Evolution From Adolescence To Adulthood. Human Relations. Vol 15 No.159 (pages1-12)

[15] Priestly,M.C.(2003).Disability: A Life Course Approach. Oxford:Blackwell Pub.

[16] Silverman,S.R : Lane, H.S and Calvert,D.R (1978).Early and Elementary Education. In Davies,H. and Silverman,S.R.(Eds).Hearing and Deafness. NewYork: Holt Rinehart and Winston.

[17] Skinner,B.F(1938).The Behavior Of Organisms: An Experimental Analysis. New York: Appleton Century Crofts.

[18] Wall,W.D(2009).Constructive Education For Special Groups: Handicapped and Deviant Children. London : Harrap, UNESCO.

[19] Winzer,M.(1990).Children With Exceptionalities: A Canadian Perspective.(2ndEd).

[20] Scarborough : Prentice-Hall Canada Inc.

[21] Zigmond,N. and Sainato,D.(2001). Socilisation Influences On Educationally Handicapped

[22] Adolescents. In Keogh, B.K (Ed).Advances in Special Education; Socialisation Influences on Exceptionality. London: Jai Press 